\title{
OVERVIEW OF COMMUNITY, PUBLIC, AND POPULATION HEALTH
}

Diana R. Mager

\section{Chapter Description}

Many terms can be used to describe settings where nurses care for community-dwelling people, creating confusion about the terminology. Often the terms community health, public health, and population health are used interchangeably. However, while they may represent similar or overlapping settings, there are subtle differences among them. The focus of this chapter is to describe key points related to these settings, including focus of care, trends, funding sources, nursing roles, and discussion of important terms. The chapter concludes with a list of key words, concepts, and critical thinking exercises. The remaining chapters of this book focus more specifically on different care settings within the domain of population health and the role of nurses therein.

\section{Populations Served in Community Health Settings}

Generally, community health nursing is considered a method to promote health and prevent disease in communities where people live, attend school, work, worship, and socialize. It is almost easier to consider "community health" as a phenomenon, rather than trying to define it in a few finite words. As such, the Centers for Disease Control and Prevention (CDC), whose role includes "tackling the biggest health problems causing death and disability to Americans" and "promoting healthy and safe behaviors, communities and environment" (CDC, n.d.-b, "CDC's Role"), has stated the following:

Working at the community level promotes healthy living, helps prevent chronic diseases and brings the greatest health benefits to the greatest number of people in need. It also helps to reduce health gaps caused by differences in race and ethnicity, location, social status, income, and other factors that can affect health. (CDC, n.d.-c, para. 2)

Based on this definition, the populations that nurses work with in communities can include any group of people who fit together based on some common thread. There are no set rules as to how such groups are assembled because any key factor describing people can be used as a similarity in forming a group. For example, groups with similar characteristics can be employees of a specific business who have difficulty with workplace air quality. Also, it can be a group of healthy expectant mothers attending classes on prenatal care. Conversely, the commonality can be presence of a disease state or illness such as diabetes, cardiovascular 
disease, or autoimmune disease. Community-based populations can also be formed related to age groups: school-age children, young adults, or infants, for example. They can be grouped by race based on one of the five racial categories: American Indian/Alaskan Native, Asian, Black/African American, Native Hawaiian/Other Pacific Islander, and White; or by ethnicity: Hispanic/Latino or Not Hispanic/Latino (U.S. Census Bureau, 2017). In this book, the term populations represents any group that shares a commonality regarding health, illness, demographics, trends, outcomes, or any other health indicator. One way that nurses can be instrumental in working with communities is by conducting a community assessment to determine needs.

\section{Community Assessment}

Community health nurses can be instrumental in assisting to identify a community's healthcare needs and priorities. The community can be large-a whole city, town, or geographic area-or it can be small-one school, one school district, a condominium complex, or a senior housing development, for example. Regardless of the location or size of the community, to ensure successful change, one first conducts an objective and thorough community needs assessment. Several published templates exist for use in the assessment process to gather and document community-specific data. Templates can also be modified to include additional information specific to the population/community being examined. Such data includes the community's history, demographics, morbidity and mortality rates, culture, socioeconomic standing, physical environment, safety, government, communication methods, and access to medical care and other resources.

Often, the first step in the assessment process is to conduct a windshield survey of the community. This survey is a snapshot of the community, as seen while walking, driving, or riding through key streets and areas. It is important to include different socioeconomic areas of the community during the windshield survey to ensure representation of different populations living in diverse areas. Industrial, residential, and business areas as well as green spaces are all important parts of the assessment, allowing for a broad view of the community. A thorough assessment includes gathering information from stakeholders, key informants, and community coalitions to help determine varied viewpoints of the community's assets, strengths, and barriers. It is beneficial to use an asset-based approach to the assessment, so that the community's assets, or strong points, can be used to help reach goals or meet community needs. Information gathered during the community assessment can then be used to develop plans to improve health outcomes. In addition to the windshield survey, public health workers gather secondary data to complete the assessment. Secondary data is information that is already gathered, analyzed, and posted for public domain.

\section{Community Funding Sources}

Communities can obtain funding to improve health outcomes in different ways. Local, state, and federal grants can be used to fund projects, educational ventures, and health promotion/ disease prevention activities. One example is the CDC's National Center for Chronic Disease Prevention and Health Promotion (NCCDPHP [2019]), which funds programs to promote 
healthy behaviors where Americans live, learn, work, and play. Their goal, through funding, is to facilitate community-based changes designed to endure over time and to impact the presence of chronic illness. Their focus is on programs that assist with smoking cessation, increasing physical activity, and improving nutrition, for example. Many such government grant opportunities exist, and businesses, groups, and/or individuals may search for them online and then apply if eligibility criteria are met.

In addition to government grants, privately owned foundations, local businesses, or other community-based organizations sometimes offer funding to enhance a community's overall health. Grant-related projects can be used in several ways: to educate people and/or healthcare professionals, to screen for various illnesses/diseases, and to conduct research on areas of concern or on health promotion/disease prevention topics. Not all grant applications are funded, as it is often a highly competitive process and applicants must meet any or all requirements set forth by the funder.

\section{Public Health}

In 1988, the Institute of Medicine (IOM) defined public health as "what we, as a society, do collectively to assure the conditions in which people can be healthy" (1988, p. 1). More recently, the CDC defined public health as "the science of protecting and improving the health of people and their communities. This work is achieved by promoting healthy lifestyles, researching disease and injury prevention, and detecting, preventing and responding to infectious diseases" (CDC Foundation, n.d., para. 1). Unlike traditional nursing care that focuses on individuals, public health focuses on care of the larger whole population. Public health officials use evidence-based knowledge to intervene in ways that support the mission of public health, which is to prevent disease, illness, and injury, and to promote health and mental health to the public. The public health system is a vast compilation of entities including public health agencies at local and state levels, healthcare professionals, public safety agencies, and many types of organizations such as human service, charity, education, youth development, recreation, arts-related, economic, philanthropic, and environmental (CDC, n.d.-e). The CDC cites 10 essential services provided by the public health arena that are categorized further under three overarching core functions of public health (see Box 1.1). The three core functions are assessment, assurance, and policy development (CDC, n.d.-e).

\section{Three Core Functions of Public Health: Assessment, Assurance, and Policy Development}

\section{Assessment}

The core function assessment includes a systematic, objective process of gathering and analyzing health data and making the information available to the public (IOM, 1988). Public health officials monitor and investigate problems, trends, and healthcare outcomes to formulate diagnoses and to determine how populations are affected immediately and long term. Data collection is a key component of assessment. Assessments can be conducted in relation to the environment, health status indicators, access to care issues, living or workplace 


\section{BOX 1.1 CORE FUNCTIONS OF PUBLIC HEALTH AND 10 ESSENTIAL PUBLIC HEALTH SERVICES}

\section{Core Function: ASSESSMENT}

1. Monitor health status to identify and solve community health problems.

2. Diagnose and investigate health problems and health hazards in the community.

\section{Core Function: POLICY DEVELOPMENT}

3. Inform, educate, and empower people about health issues.

4. Mobilize community partnerships and action to identify and solve health problems.

5. Develop policies and plans that support individual and community health efforts.

\section{Core Function: ASSURANCE}

6. Enforce laws and regulations that protect health and ensure safety.

7. Link people to needed personal health services and assure the provision of healthcare when otherwise unavailable.

8. Assure competent public and personal healthcare workforce.

9. Evaluate effectiveness, accessibility, and quality of personal and population-based health services.

10. Research for new insights and innovative solutions to health problems.

Source: From Centers for Disease Control and Prevention. (n.d.-a). Core functions of public health and how they relate to the 10 essential services. Retrieved from https://www.cdc.gov/nceh/ehs/ephli/core_ess.htm

conditions, education, safety, socioeconomic concerns, prevalence of illness and disease, morbidity and mortality rates, or almost anything that can affect the public's health and/or well-being.

\section{Assurance}

Public health's mission is to assure the health of the people. The core function assurance is designed to ensure that quality services are available to the public. This is accomplished by enforcing laws and regulations, referring people to necessary services, assuring the workforce is competent, and evaluating available health services. Examples include requiring licensure for RNs and other healthcare providers, mandatory vaccinations for school children, and monitoring restaurant kitchens to ensure they meet health requirements, to name a few.

\section{Policy Development}

When resources are applied to public health needs, great strides can be made in health outcomes. For example, in the United States, overall health has improved in part due to educational, research, and public health initiatives (National Center for Health Statistics [NCHS], 2017). Policy or laws and regulations can best be developed when objective, scientific data is used to validate the need for change, and, thus, policy development is a core function 
of public health. Examples of policy development include creating guidelines and laws for healthcare reform, instituting rules related to Medicare and Medicaid funding, and administering health insurance to underprivileged children.

\section{Population Health}

Population health has been defined as "an opportunity for health care systems, agencies and organizations to work together to improve the health outcomes of the communities they serve" (MHA@GW Staff, 2015, para. 4). Thus, population health focuses on a broad range of factors that affect health outcomes for groups of people.

\section{Population Health: National Trends and Outcomes}

The U.S. government gathers data on health outcomes and trends across the life span with a goal of instituting initiatives, programs, and policies to enhance future health outcomes and eliminate health disparities. For example, each year the NCHS, a component of the CDC, compiles a report of the overall health status of the United States. Over a 40-year period (1975-2015), the U.S. population increased by 105 million people, from 216.0 to 321.4 million, respectively (NCHS, 2017). The increased population was accompanied by changes in demographics. For example, in 1980, approximately $20 \%$ of the U.S. population identified themselves as either racial or ethnic minorities, a number that has risen to $38.4 \%$ as of 2015 (NCHS, 2017). As people live longer and the country becomes more ethnically and racially diverse, our healthcare system will need to consider demographic changes when planning for the population's health needs.

The United States is considered a high-income country, spending significantly large sums of money on the healthcare system. Despite the cost of U.S. healthcare, data suggests that Americans have poorer health status and shorter life expectancies than countries of similar economic status (Woolf \& Aron, 2013). It is important to determine factors contributing to these findings. Population health includes examination of trends and related demographic, socioeconomic, and behavioral factors that influence outcomes.

\section{Demographic and Socioeconomic Determinants}

In the United States, health status is tracked through the government's collection and analysis of samplings of health, demographic, and socioeconomic data. Demographic data includes information such as age, gender, race, marital status, education, income, and/or occupation. Health data includes examination of incidence of illness, disease, injury and disability, nutritional information, and related healthcare expenditures. The government then uses this data to study trends and impact on overall population health (U.S. Department of Health and Human Services [USDHHS], n.d.-b). While certain biological factors such as age, genetics, or gender can have positive or negative effects on health, outcomes are also affected by social determinants.

Social determinants of health are potentially modifiable factors, and are defined by the Office of Disease Prevention and Health Promotion (ODPHP) as, "conditions in the 
environments in which people are born, live, learn, work, play, worship, and age that affect a wide range of health, functioning, and quality-of-life outcomes and risks" (n.d., "Understanding Social Determinants of Health"). Healthy People 2020 addresses how social determinants of health can be addressed to promote good health for all Americans. Currently in the United States, life expectancy differs by as much as 15 years depending on factors such as where people live, income and education levels, race, and access to healthcare (American Public Health Association [APHA], n.d.-b). As such, the primary goal of the USDHHS is to protect the health of all Americans and to provide essential human services with special focus on those people or groups who are least able to help themselves (USDHHS, n.d.-a, 2016).

\section{Trends}

\section{Life Expectancy}

One way to examine population health is through life expectancy. Life expectancy is defined as how long one can expect a group of people to live, based on prior data from similar groups (NCHS, 2017). As of 2015, life expectancy from birth in the United States was 78.8 years, up 2 years from 2000. Age adjustments are sometimes made when different age distributions exist within a group. For example, if there are an excessive number of very old or very young people in a group, then statisticians may adjust ages when calculating data to allow for a more accurate comparison between groups. Table 1.1 represents trends in age-adjusted deaths per 100,000 people in the United States (NCHS, 2017).

\section{TABLE 1.1 Death Rates in the United States}

\begin{tabular}{|l|c|c|}
\hline \multicolumn{3}{|c|}{ AGE-ADJUSTED DEATH RATES BY DISEASE PER 100,000 PEOPLE (2015) } \\
\hline & 2000 & 2015 \\
\hline Heart disease & 257.6 & 168.5 \\
\hline Cancer & 199.6 & 158.5 \\
\hline Unintentional injuries & 34.9 & 43.2 \\
\hline Chronic lower respiratory diseases & 44.2 & 41.6 \\
\hline Stroke & 60.9 & 37.6 \\
\hline Alzheimer's disease & 18.1 & 29.4 \\
\hline Diabetes & 25.0 & 21.3 \\
\hline Influenza and pneumonia & 23.7 & 15.2 \\
\hline Kidney diseases & 13.5 & 13.4 \\
\hline Suicide & 10.4 & 13.3 \\
\hline
\end{tabular}

Source: From National Center for Health Statistics. (2017). Health, United States, 2016: With chartbook on long-term trends in health. Hyattsville, MD. Retrieved from https://www.cdc.gov/nchs/data/hus/ hus16.pdf 
Tracking trends over time is valuable in determining whether interventions have been effective in decreasing morbidity rates and/or disease prevalence. Significant findings in Table 1.1 include the decreases in deaths from heart disease by $65 \%$ and from strokes by nearly $62 \%$ over 15 years. These findings, as well as decreased cancer deaths, are worthy national accomplishments. Health officials work to determine trends that show either improving or declining statistical evidence. Using preventive measures (primary prevention), early detection (secondary prevention/screenings), and promoting healthier lifestyles to decrease risk have all contributed to improved outcomes (NCHS, 2017). However, there is always additional research required to determine why certain disease rates increase while others decrease.

\section{Socioeconomic Status}

There is a documented correlation between socioeconomic status and health outcomes. Often, lower socioeconomic status is associated with poorer health outcomes (Woolf \& Aron, 2013). The U.S. Institute for Healthcare Improvement (IHI) strives to remove "differences in access, treatment, and outcomes between individuals and across populations that are systemic, avoidable, predictable, and unjust" (IHI, n.d.-b, para. 2). Differences in the quality of care provided and access to care in general result in inequities or disparities between groups of people. Therefore, the IHI collaborates with public health officials to prevent and remove such disparities and inequities. Although many factors contribute to inequity, a key contributor is lack of health insurance (USDHHS, 2016). Other factors include lack of access to quality healthcare and/or to preventive care.

\section{Tobacco Use}

It is well-documented that tobacco use contributes to adverse health outcomes such as coronary artery disease, stroke, cancer, chronic lung disease, low birth weight, and infant mortality (Woolf \& Aron, 2013). While smoking has decreased nationally since 1974, as of 2015, smoking was the leading cause of preventable disease, disability, and death in the United States, increasing the risk of heart disease, stroke, lung cancer, and other types of cancer. Trends indicate that adults who have not earned a high school diploma are more than four times more likely to smoke than those who have earned a bachelor's degree or higher (NCHS, 2017). This is an example of a disparity between groups.

\section{Obesity, Hypertension, and Diabetes}

Data gathered since 1999 suggests that the prevalence of obesity is increasing. Despite the Healthy People 2020 goal of obtaining 30.5\% prevalence of obesity among adults, current data suggests that over one-third (36.5\%) of U.S. adults were considered obese from 2011 to 2014, with higher rates in women (38.3\%) than men (34.3\%). During that same time, children aged 2 to 5 years, 6 to 11 years, and 12 to 19 years had obesity prevalence rates of $8.9 \%, 17.5 \%$, and $20.5 \%$, respectively. Non-Hispanic Asians had a lower prevalence of obesity $(11.7 \%)$ than non-Hispanic White (34.5\%), Hispanic (42.5\%), and non-Hispanic Black (48.1\%) adults (Ogden, Carroll, Fryar, \& Flegal, 2015). Obesity contributes to hypertension and diabetes and, as such, can lead to several related health issues such as heart disease and stroke among others (CDC, n.d.-d). This too is an example of how different groups experience different risk factors leading to disparate disease rates. 


\section{IHI: Triple Aim}

Although the United States spends more on healthcare than any other nation worldwide, many other health systems outperform the United States regarding healthcare cost and outcomes (IHI, n.d.-c). The IHI suggests a three-dimensional approach to optimize our healthcare system and, as such, has developed the Triple Aim framework that includes:

1. Improving the patient experience of care (including quality and satisfaction);

2. Improving the health of populations; and

3. Reducing the per capita cost of health care (IHI, n.d.-c, para. 1)

The Triple Aim fits well within the framework of population health and recommends several interventions to promote successful health outcomes including "identification of target populations; definition of system aims and measures; development of a portfolio of project work that is sufficiently strong to move system-level results; and rapid testing and scale up that is adapted to local needs and conditions" (IHI, n.d.-c, "Approach"). Further, the IHI believes that to accomplish these goals, the United States must

harness a range of community determinants of health, empower individuals and families, substantially broaden the role and impact of primary care and other community based services, and assure a seamless journey through the whole system of care throughout a person's life. (IHI, n.d.-c, "Approach")

\section{Working Upstream in Community, Public, and Population Health}

The concept of working "upstream" has been linked to population health initiatives and is a way to address various socioeconomic factors that can affect health (Manchanda, 2016). The analogy to a stream can be viewed in this way: It is preferable to work with a patient population early enough (upstream) before disease onset, so that they can prevent illness and disability later on (downstream) when disease sequela may be advanced. The Upstream network expresses the importance of "income, employment, education, early childhood development, housing, nutrition, and the wider environment" (n.d., "Why 'upstream'?") and how these factors can influence health positively or negatively. Many believe that to promote the Triple Aim, healthcare professionals need to work in an "upstream manner," where socioeconomic factors that contribute to health and combine medical care with public health initiatives are addressed (Manchanda, 2016).

\section{Role of the Nurse in Community, Public, and Population Health}

Nurses have the unique opportunity to work in a variety of community-based settings. When the public think of nurses, they often relate nursing to working in acute care or hospitals. However, the purpose of this text is to highlight the critical role that nurses play in 
communities and how they contribute to population health. Common settings include, but are not limited to, long-term and home healthcare institutions; schools and day-care centers; homeless shelters; college campuses; occupational health (work settings); senior housing; local, state, and federal departments of health; hospice and palliative care centers; mental health facilities; women's health organizations; and primary care centers. Various settings are highlighted in upcoming chapters while this section describes an overview of the nurse's role in population health.

\section{Education}

Nurses, like any healthcare professional, cannot force people to make healthy choices or selfcare decisions. However, they can assist people to embrace changes that may lead to better health outcomes. Patient education is a key element in promoting patient success in following medical regimens. Additionally, education can be used to encourage behavior changes necessary to improve health. Regardless of the setting, population, or disease process, people require education about illnesses, treatments, and preventive measures, so that they are better informed to weigh risks versus benefits when making choices. Making credible, evidence-based information available to patients in an understandable way is a critical nursing role within any population or setting. The level of education/literacy, primary language spoken, and presence of hearing loss are important factors to consider when educating people. For example, a written brochure is not helpful to a person who cannot read, any more than verbal instructions can assist a person who cannot hear or understand the language.

One way to ensure that teaching has been effective is to use the teach-back method, or asking the person to repeat, in his or her own words, the instructions (IHI, n.d.-a). According to the IHI, providers should always use the teach-back method. Demonstration with return demonstration is also an effective confirmation of a patient's understanding. Examples include watching a person prefill his or her weekly medication box, use a steroidal inhaler, or self-inject insulin. Education also includes offering information to patients regarding adverse outcomes that may occur when a regimen is not followed. For example, ample evidence exists about morbidity, life expectancy, and mortality related to diseases for smokers versus nonsmokers, as well as for people who control their blood sugar or blood pressure versus those who do not. Nurses play an important role in delivering this kind of information and in referring people to resources that may aid in changing behaviors.

\section{Referrals}

Collaboration is one of the true benefits of working in the healthcare field. A single provider cannot meet all the needs of every patient; therefore, an important nursing role includes knowing when to suggest a referral to another discipline. Beyond physicians and nurses, rich referral sources include such disciplines as physical, occupational, and speech therapy; social services; dietary and nutrition services; counseling, mental health, and religious services; pain management; palliative and hospice care services; and personal care, companions, and/or housekeeping services. Knowing when to request a referral from another licensed or unlicensed provider is critical within the nursing role. 


\section{Advocacy and Policy}

Being a strong patient advocate is fundamental to nursing. Advocacy includes doing what is in the best interest of the patient and can take the shape of many forms. Examples of advocacy include referring a patient to available recourse based on need and socioeconomic status; speaking to providers on the patient's behalf; helping patients ask questions of their providers; and helping them to negotiate the healthcare system so that their needs are met. These examples are common, and nurses typically take part in such advocacy daily, even hourly. However, the American Nurses Association (ANA) suggests that another key nursing role includes legislative and political advocacy, stating, "With energetic participation in advocacy, every nurse can help the profession to improve and move to higher levels" (ANA, n.d.-a, para. 2). There are currently 3.6 million RNs in the United States (ANA, n.d.-b). While nurses may not necessarily think of their primary role as advocating for policy, law, reform, and/or the creation of public health programs, 3.6 million people can play a critical role in promoting change.

\section{Care Provision}

Educating patients, advocating for them, and referring them to necessary services are all small pieces of the care-provision puzzle. Other pieces include performing nursing assessments, creating mutually agreed-on goals of care, intervening, and evaluating outcomes. Nurses help the public to build the puzzle while being mindful of educational, cultural, social, racial, ethnic, economic, and religious differences. Once the puzzle pieces are in place, a picture emerges. As nurses, we hope that the picture is perfect-free of disparities, disease, illness, and injury-and that it is focused on prevention and health promotion. Unfortunately, as with any puzzle, sometimes there are pieces missing, and this detracts from the perfect picture of health. When this occurs, care provision shifts, and patients need more acute carelevel medical and nursing attention. The goal of population health is to educate people in a proactive way so that they can avoid missing pieces in the future and, as such, improve their long-term health outcomes.

\section{Clinical Reasoning Activities With Rationale}

1. Conduct research to locate a community assessment template. Discuss the key components on the template. Describe how a community health nurse would gather the data required in the template.

Points of significance with rationale: The community health nurse would start by conducting a windshield survey of the community. This includes being driven down key streets (main street, side streets, urban and rural parts of the community; higher and lower income areas; school districts; shopping districts; through places where people worship). Key stakeholders and informants can be used to gather assessment data. In addition, the nurse gathers secondary data from sources such as government websites. During the assessment, it is helpful to determine if there are community coalitions. 
2. Which of the three core functions of public health relate to each of the following?

a. Providing licensure to RNs

Answer: Assurance. Rationale: Assuring the public of a safe workforce

b. Gathering data to determine if evacuation routes are safe to travel on after a hurricane

Answer: Assessment. Rationale: Data gathering is always part assessment, either before, during, or after the event

c. Using morbidity data to validate the need for additional funding for public health programs in one school district

Answer: Policy development. Rationale: Morbidity data, or how health has been affected, is an objective way to demonstrate outcomes that could warrant changes in policy and/or funding of programs

d. Having a school nurse send a letter to parents that vaccines need to be updated before a child can come back to school

Answer: Assurance. Rationale: By having all the children vaccinated, it prevents others in the classes from being exposed to infectious diseases and, as such, assures the health of the public

\section{Key Terms}

American Public Health Association (APHA): The role of the APHA is to promote the health of all people by strengthening the public health profession, and advocating for public health issues and policy, with a mission to improve the health of the public and achieve health equity for all (APHA, n.d.-a).

Assessment: includes a systematic, objective process of gathering and analyzing health data and making the information available to the public (IOM, 1988).

Asset-based approach: Gathering community data based on the assets or positive attributes of the community. Assets could be anything that the community sees as beneficial such as access to healthcare, presence of a hospital, safety, emergency evacuation plans, sense of community, and others.

Assurance: A core function of public health, designed to ensure that quality services are available to the public.

Community coalitions: People, agencies, healthcare professionals, government officials, or other groups who work collaboratively to improve public health outcomes. Coalitions are often compared to resources for a community. Examples may include local health departments, places of worship, shelters, and community health centers.

Core functions of public health: The three core functions are assessment, assurance, and policy development (see Box 1.1).

Demographic data: Identifying information about people such as age, gender, race, marital status, education, income, and/or occupation. 
Health indicators: Factors designed to provide a standard way to compare health between groups over time. Examples of health indicators include mortality rates (death rates), morbidity data (related to disease, illness, and health status), health-related behaviors (tobacco use, physical activity, diet, nutrition, alcohol use, etc.), and access to healthcare (National Information Center on Health Services Research and Health Care, n.d.).

Key informants: People in a community who know the history, the culture, the "back story" that may not be known to others. They provide information about the current state of the situation and knowledge of the history of the situation.

Morbidity rates: The number of people who have a disease or illness divided by the total number of people in the population over a specific time.

Mortality rates: The number of deaths occurring over a specific period.

Policy development: A core function of public health that include creating guidelines, laws and rules to improve or protect the public's health.

Population: Any group that shares a commonality regarding health, illness, demographics, trends, outcomes, or any other health indicator.

Population health: A focus on broad factors that affect the health outcomes for groups of people who share a commonality.

Public health: Focus of care is on the larger population, whose mission is to prevent disease, illness, and injury and to promote health and mental health to the public.

Race and ethnicity: The U.S. Census Bureau collects racial and ethnic data based on guidelines set by the U.S. Office of Management and Budget (OMB). This data is gathered in part to ensure equal access to healthcare and to eliminate disparities between groups. There are five categories of race, indicating the social group that a person self-identifies with: American Indian/Alaskan Native, Asian, Black/African American, Native Hawaiian/Other Pacific Islander, and White. People can select more than one race if applicable. Ethnicity has been broken down into only two categories: Hispanic/Latino and Not Hispanic/Latino (U.S. Census Bureau, 2017).

Secondary data: Data that has already been gathered, analyzed, and posted for public domain. Examples include morbidity and mortality data; vital statistics; and socioeconomic and educational data.

Social determinants of health: Potentially modifiable factors, and are defined by the ODPHP as, "conditions in the environments in which people are born, live, learn, work, play, worship, and age that affect a wide range of health, functioning, and quality-of-life outcomes and risks" (n.d., "Understanding Social Determinants of Health").

Stakeholders: Individuals or groups who have a vested interest (something to gain or to lose) regarding a given situation in the community. For example, if a nuclear plant is going to be built in a community, key stakeholders would include residents, business owners, neighbors, the owner/designers of the plant, government, people "for" and "against" the plant, and suppliers. A stakeholder can be anyone who is affected by a situation.

Triple Aim: A framework that focuses on improving the patient experience, the health of populations, and the cost of healthcare (IHI, n.d.-c). 
Windshield survey: A snapshot of the community, as seen while walking, driving, or riding through key streets and areas, including different socioeconomic and geographic areas of the community.

\section{References}

American Nurses Association. (n.d.-a). Advocacy. Retrieved from https://www.nursingworld.org/practice -policy/advocacy

American Nurses Association. (n.d.-b). Workforce. Retrieved from https://www.nursingworld.org/practice -policy/workforce

American Public Health Association. (n.d.-a). About APHA. Retrieved from https://apha.org/about-apha

American Public Health Association. (n.d.-b). Generation public health. Retrieved from https://apha.org/ what-is-public-health/generation-public-health

CDC Foundation. (n.d.): What is public health? Retrieved from https://www.cdcfoundation.org/what -public-health

Centers for Disease Control and Prevention. (n.d.-a). Core functions of public health and how they relate to the 10 essential services. Retrieved from https://www.cdc.gov/nceh/ehs/ephli/core_ess.htm

Centers for Disease Control and Prevention. (n.d.-b). Mission, role and pledge. Retrieved from https://www. cdc.gov/about/organization/mission.htm

Centers for Disease Control and Prevention. (n.d.-c). NCCDPHP: Community health.. Retrieved from https://www.cdc.gov/nccdphp/dch/about/index.htm

Centers for Disease Control and Prevention. (n.d.-d). Overweight and obesity: Adult obesity facts. Retrieved from https://www.cdc.gov/obesity/data/adult.html

Centers for Disease Control and Prevention. (n.d.-e). The public health system \& the 10 essential public health services. Retrieved from https://www.cdc.gov/stltpublichealth/publichealthservices/ essentialhealthservices.html

Institute for Healthcare Improvement. (n.d.-a). Always use teach back! Retrieved from http://www.ihi.org/ resources/Pages/Tools/AlwaysUseTeachBack!.aspx

Institute for Healthcare Improvement. (n.d.-b). Health equity. Retrieved from http://www.ihi.org/Topics/ Health-Equity/Pages/default.aspx

Institute for Healthcare Improvement. (n.d.-c). IHI Triple Aim initiative. Retrieved from http://www.ihi .org/Engage/Initiatives/TripleAim/Pages/default.aspx

Institute of Medicine. (1988). The future of public health. Washington, DC: National Academy Press.

Manchanda, R. (2016). Upstream medicine. Retrieved from https://www.medscape.org/viewarticle/ 864173_2

MHA@GW Staff. (2015). What is population health? Retrieved from https://mha.gwu.edu/what-ispopulation-health

National Center for Chronic Disease Prevention and Health Promotion (Updated 2019). Retrieved from https://www.cdc.gov/chronicdisease/index.htm

National Center for Health Statistics. (2017). Health, United States, 2016: With chartbook on long-term trends in health. Hyattsville, MD: Author. Retrieved from https://www.cdc.gov/nchs/data/hus/hus16.pdf

National Information Center on Health Services Research and Health Care. (n.d.). Health indicators overview transcript. Retrieved from https://www.nlm.nih.gov/nichsr/healthindicators/Health_ Indicators_Overview_Transcript.html

Office of Disease Prevention and Health Promotion. (n.d.). Social determinants of health. Retrieved from https://www.healthypeople.gov/2020/topics-objectives/topic/social-determinants-of-health

Ogden, C., Carroll, M., Fryar, M., \& Flegal, K. (2015). Prevalence of obesity among adults and youth: United States, 2011-2014 [NCHS data brief no. 219]. Retrieved from https://www.cdc.gov/nchs/data/ databriefs/db219.pdf

Upstream: Institute for a Health Society. (n.d.). About Upstream. Retrieved from http://www .thinkupstream.net/about_upstream 
U.S. Census Bureau. (2017). Race and ethnicity. Retrieved from https://www.census.gov/mso/www/training/ pdf/race-ethnicity-onepager.pdf

U.S. Department of Health and Human Services. (2016). Fiscal year 2017 annual performance plan and report. Retrieved from https://www.hhs.gov/sites/default/files/fy2017-performance-plan_remediated.pdf

U.S. Department of Health and Human Services. (n.d.-a). About HHS. Retrieved from https://www .hhs.gov/about/index.html

U.S. Department of Health and Human Services. (n.d.-b). Freedom of Information Act: SORN 09-20-0164. Retrieved from https://www.hhs.gov/foia/privacy/sorns/09200164/index.html

Woolf, S. H., \& Aron, L (Eds.). (2013). US health in international perspective: Shorter lives, poorer health. Washington, DC: National Academies Press. 